Global Nest: the Int. J. Vol 6, No 2, pp 167-175, 2004

Copyright $\odot 2004$ GLOBAL NEST

Printed in Greece. All rights reserved

\title{
WEATHERING OF LEAD IN FORT IRWIN FIRING RANGE SOILS
}

\author{
D. DERMATAS \\ M. DADACHOV \\ P. DUTKO \\ N. MENOUNOU \\ P. ARIENTI \\ G. SHEN*
}

\author{
W.M. Keck Geoenvironmental Laboratory, \\ Center for Environmental System, \\ Stevens Institute of Technology, \\ Hoboken, NJ 07030, USA
}

Received: $26 / 08 / 03$

* to whom all correspondence should be addressed:

Accepted: 02/03/04

Fax: + 201-216-8212

e-mail: gshen@stevens-tech.edu

\section{ABSTRACT}

This paper investigates the physical and chemical transformation of metallic lead $(\mathrm{Pb})$ in Ft. Irwin firing range soils. Soil samples were collected from berms of two small arms firing ranges, an active one and an abandoned one, located in the Mojave desert. Pb bullet fragments found in field samples were analyzed by means of X-ray diffraction (XRD) and scanning electron microscopy (SEM) in order to determine the mechanism of metal breakdown in desert climates. Moreover, in order to further elucidate metallic $\mathrm{Pb}$ surface reactions, the process by which $\mathrm{Pb}$ fragments are subjected to field weathering conditions was simulated in the laboratory by performing wetting and drying cycle tests on the surface of metallic $\mathrm{Pb}$ specimens. Results indicated that metallic $\mathrm{Pb}$ bullet fragments recovered from the active range field samples were primarily covered by surface layers of cerussite and hydrocerussite, but litharge was also identified. In the abandoned range, hydrocerussite and metallic $\mathrm{Pb}$ were the predominant $\mathrm{Pb}$ species, but laurionite was also identified. The wetting and drying test results also confirmed the predominant presence of cerussite and hydrocerussite. In addition, the presence of copper (Cu). Overall, it seems that in these high $\mathrm{pH}$ desert environments, $\mathrm{Pb}$ would eventually form insoluble secondary minerals and therefore, its mobility is expected to be quite limited.

KEYWORDS: bullet, cerussite, hydrocerussite, laurionite, plumbonacrite, XRD, SEM, FTIR.

\section{INTRODUCTION}

Lead has been a metal of choice for ammunitions due to its favorable physical characteristics such as low melting point $\left(327.4^{0} \mathrm{C}\right)$, its malleability, high density $\left(11.34 \mathrm{~g} \mathrm{~cm}^{-3}\right)$ and relatively high resistance to corrosion. However, elemental $\mathrm{Pb}$ and also many of its compounds are toxic to both humans and animals at elevated levels. Children under 6 years of age are particularly vulnerable to the toxic effects of $\mathrm{Pb}$ including decreased intelligence quotients (IQs) and stunted growth (Xintiuas,
1992). Excessive $\mathrm{Pb}$ exposure to a fetus can cause lower birth weight, premature birth and decreased mental ability in the infant. In adults, it can result in deferred reaction, anemia, possible memory effects, high blood pressure as well as severe damage to the brain and kidneys, and even miscarriage in pregnant women. For all these reasons, $\mathrm{Pb}$ is now ranked as the one of the most hazardous substances on the U.S. Environmental Protection Agency (USEPA) priority list. Comparing the application of $\mathrm{Pb}$ in different 
industries, there were up to 800 tons of metallic $\mathrm{Pb}$ being deposited in the soil of shooting ranges in Denmark, whereas only 250 tons were used as additives in vehicle fuel (Jorgensen and Willems, 1987). In the US, about 38,500 metric tons of $\mathrm{Pb}$ were used in ammunition or bullet related products in 2001 (USGS, 2002), becoming the second largest consumer of $\mathrm{Pb}$ behind the storage battery industry. Excluding storage batteries, the ammunition industry accounts for more than half of the total $\mathrm{Pb}$ usage. Consequently, firing ranges are considered potentially significant sources of $\mathrm{Pb}$ contamination to the soil and ambient groundwater and are therefore under increasing scrutiny (Rooney et al., 1999; Craig, 1999). A variety of studies on firing ranges indicated $\mathrm{Pb}$ levels in soils were over $3,000 \mathrm{mg} \mathrm{kg}^{-1}$, which greatly exceeds the USEPA screening level of $400 \mathrm{mg} \mathrm{kg}^{-1}$ (USEPA, 1996). This is true regardless whether firing ranges are still in service or have been abandoned in some cases for more than 30 years (Murray et al., 1997).

In general, the corrosion process of metallic $\mathrm{Pb}$ is highly dependent on a variety of ambient conditions such as geochemical and geotechnical properties of the surrounding soils, climate, site geology, etc. Once fired into the soil matrix, $\mathrm{Pb}$ bullets would eventually decompose to a particulate or dissolved form by weathering or oxidation processes. The most common $\mathrm{Pb}$ species found in temperate soils are cerussite $\left(\mathrm{PbCO}_{3}\right)$, hydrocerussite $\left(\mathrm{Pb}_{3}\left(\mathrm{CO}_{3}\right)_{2}(\mathrm{OH})_{2}\right)$, litharge $(\mathrm{PbO})$ and anglesite $\left(\mathrm{PbSO}_{4}\right)$ (Lin Z et al., 1995; Astrup et al., 1999; Lanndsberger et al., 1999; Bruell et al., 1999). The amount and type of $\mathrm{Pb}$ species encountered in different firing range sites depend on site-specific characteristics. In spite of the solubility of these secondary $\mathrm{Pb}$ minerals being quite low under normal field $\mathrm{pH}$ conditions, under acidic $(\mathrm{pH}<5)$ or basic $(\mathrm{pH}>10)$ conditions, they are likely to transform into dissolved forms and therefore become quite mobile.

Overall, even though there have been numerous studies involving firing ranges in temperate climates, there have been no studies focusing on desert climates. The weathering of $\mathrm{Pb}$ could be quite unique in desert areas where moisture availability and temperatures are drastically different than in temperate climates and where possibly ample amounts of salts concentrate in the soil pore matrix. In the present study soil samples were collected from berms of two small arms firing ranges, an active one and an abandoned one, located in the Mojave desert. Mineralogical and micromorphological analyses were performed on the collected samples in order to determine the mechanism of metal breakdown in desert climates. Moreover, in order to further elucidate metallic $\mathrm{Pb}$ surface reactions, the process by which $\mathrm{Pb}$ fragments are subjected to field weathering conditions was simulated in the laboratory by performing wetting and drying cycle tests on the surface of metallic $\mathrm{Pb}$ specimens. Overall, the primary objectives of this study are to:

Elucidate metallic $\mathrm{Pb}$ surface reactions

Determine the mechanisms of $\mathrm{Pb}$ weathering in desert climates

Identify the associated physico-chemical transformations of metallic $\mathrm{Pb}$

Establish a laboratory simulation method to investigate metallic $\mathrm{Pb}$ weathering in soil environments.

\section{MATERIALS AND EXPERIMENTAL METHODS: Site Description Physical geography}

The study area is the National Training Center (NTC) at Fort Irwin, California in the north-central part of the Mojave Desert, which is part of the Basin and Range Province of the southwestern United States. Based upon a study of the local geology, the Mojave area consists mainly of: 1)playa - Coyote Lake and its associated lacustrine deposits; 2) sand sheets and dunes derived from the playa; 3) a variety of alluvial fans that lie on the bajada surface between the playas in the bolson and the surrounding uplands; 4) hilly outcrops of crystalline igneous and metamorphic rocks that make up the regional basement (schists, gneisses, and granitoids); 5) rocks of Tertiary age that include sandstones, coarse conglomerates, volcanic ash beds and flows of varying composition; and 6) a rugged, structurally complex block of diverse lithology.

\section{Climate}

The climate outside the high, rugged mountain regions is hot and arid with desert scrub vegetation being the predominant feature. Present daily average temperatures are $35^{\circ} \mathrm{C}$ but afternoon summer temperatures are often in excess of 45 degrees. Winds may be strong resulting in the occasional development of sandstorms, snow is 
rare and nights are only occasionally below freezing. Rainfall events, even though of limited occurrence, are normally intense and of short duration with excessive runoff and little water percolation into the soil. In this arid environment, evaporation rates typically exceed the precipitation rates. In some cases, rain vaporizes even before it reaches the ground surface, which provides ideal conditions for the accumulation of soluble chemical species in the soils, which would in turn lead to the precipitation of a variety of evaporitic salts in the soil pore matrix. In particular, past climatic changes in the form of frequently alternating cool-moist and warm-dry periods have led to the formation of strong horizon areas particularly those of translocated clays and carbonate minerals (Nettleton et al., 1975).

\section{Soil}

Soil samples were collected from two different firing sites, Range 5 and Goldstone, within the NTC. Range 5 is currently active while the Goldstone firing range has been abandoned for more than 20 years. Although both sites are subjected to similar weathering conditions, there are a variety of apparent differences between them. Range 5 soil was characterized as well graded sand with silt whereas the Goldstone soil, a much finer material, was classified as inorganic clay of medium plasticity which will then have the tendency to cushion the bullets upon impact. A preliminary study indicated that Range 5 soils were composed mostly of granite crystalline minerals ( $>95 \%$ by weight) such as quartz, various isomorphically substituted Albite-Microcline, Orthoclase series and Muscovite. The Goldstone soils were composed of Quartz, Cristobalite (>70\% by weight) and various isomorphically substituted Albite-Microcline, Orthoclase series, Muscovite, Calcite, and Gypsum. The mineral Leikosphenite is also found occasionally. The primary clay minerals found in the fine fraction of soil samples from both sites (Range 5 and Goldstone) are Montmorillonite, Illite and Kaolinite. Metallic $\mathrm{Pb}$ bullet fragments of various sizes, with fresh (non-oxidized) and oxidized surfaces were also recovered. Finally, it is also likely that finely dispersed $\mathrm{Pb}$ particles and aerosols are chemically adsorbed onto soil clay minerals and iron oxides.

\section{Experimental Methods}

The following methods and procedures were applied to the study of $\mathrm{Pb}$ contaminated Fort Irwin soils:

\section{Optical, polarizing and scanning electron microscopy (SEM)}

Samples were studied using Nikon optical (SMZ1000) and polarizing (Eclipse E-600) microscopes and a Zeiss Scanning Electron Microscope (SEM).

\section{$X$-ray powder diffraction (XRD)}

$\mathrm{X}$-ray powder diffraction (XRD), is an instrumental technique that is used to identify minerals, as well as other crystalline materials. In the current soil investigations, XRD complements other mineralogical methods, including optical light microscopy, polarizing microscopy, and scanning electron microscopy. XRD provides with a fast and reliable tool for routine mineral identification. It is particularly useful for identifying fine-grained minerals and mixtures or intergrowths of minerals, which cannot be resolved by other methods. Stepscanned XRD data for the powders were collected by mean of a Rigaku DXR-300 computerautomated diffractometer using Bragg-Brentano geometry. The samples were powdered and sieved through a No.200 $(\sim 75 \mu \mathrm{m})$ sieve. The X-ray source was a $\mathrm{Cu}$ anode operating at $40 \mathrm{kV}$ and 30 $\mathrm{mA}$ using $\mathrm{CuK} \alpha$ radiation with a diffracted beam graphite-monochromator. Data were usually collected between $3^{0}$ and $70^{\circ}$ in 2 theta with a step size of $0.05^{\circ}$ and count time of 5-10 seconds per step. Silicon powder (NBS $640 \mathrm{a}=5.43088$ ) was used to estimate 2 theta values. The data was collected using 10 divergence slit and a $0.15 \mathrm{~mm}$ receiving slit. To prevent beam overflow at low angles, a sample length of $4 \mathrm{~cm}$ was used. The data were corrected for intensity aberrations with a diffractometer calibration curve for the BraggBrentano goniometric dimensions.

\section{Micro Fourier Transform Infrared Spectroscopy ( $\mu$ FTIR)}

Infrared, or IR, spectroscopy is a type of vibrational technique where molecular vibrations are analyzed. In this study, Micro FTIR ( $\mu$ FTIR) data of were collected at a resolution of $4 \mathrm{~cm}^{-1}$ on reflectance mode from well-polished surfaces of $\mathrm{Pb}$ pieces using a ThermoNicolet FTIR equipped with a Centaurus microscope. Results of $\mu$ FTIR and 


\section{Range 5- Lead minerals}

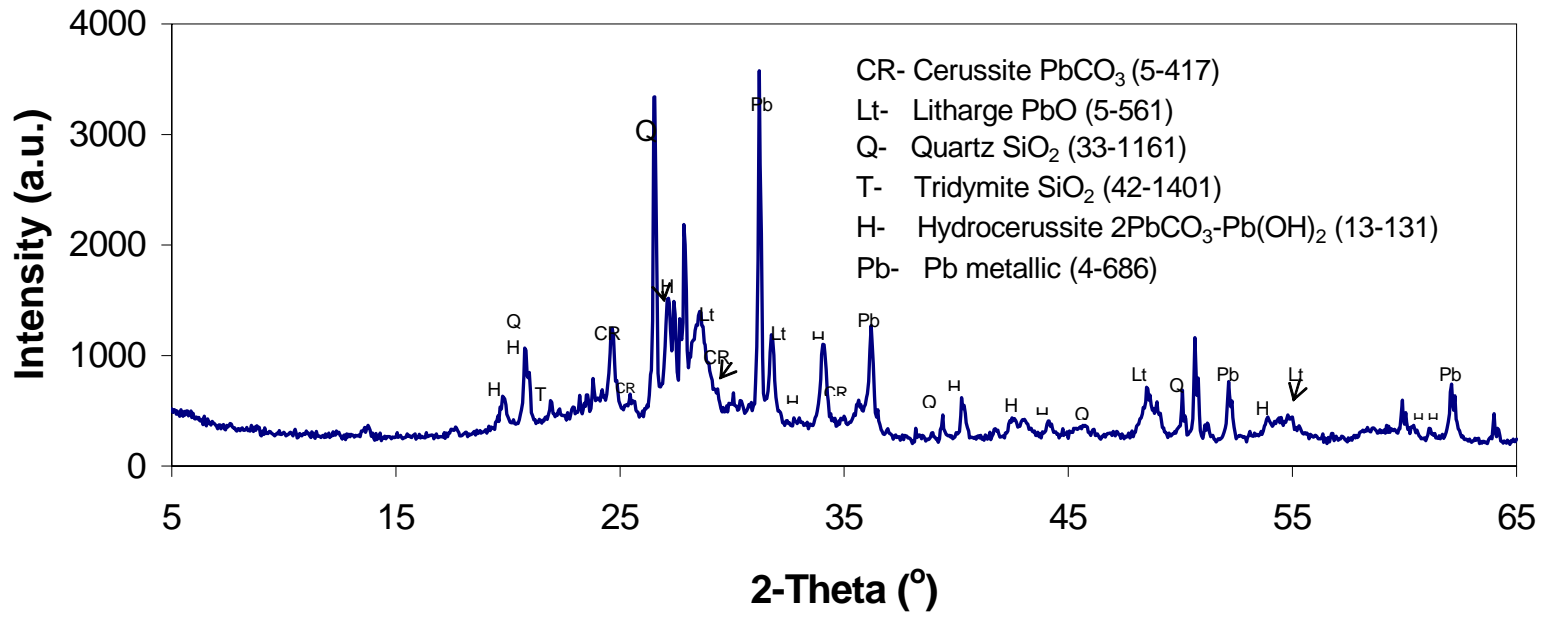

Figure 1. Diffraction pattern of crust minerals of metallic $\mathrm{Pb}$ particles from the Range 5 site.

SEM were combined to provide a more thorough description of $\mathrm{Pb}$ weathering-induced transformations.

\section{Laboratory modeling of metallic $\mathrm{Pb}$ interaction with soil}

In order to further elucidate metallic $\mathrm{Pb}$ surface reactions, the process by which $\mathrm{Pb}$ fragments are subjected to field weathering conditions was simulated in the laboratory by performing wetting and drying cycle tests on the surface of metallic $\mathrm{Pb}$ specimens. A disc of metallic $\mathrm{Pb}$ was prepared having a thickness of $3 \mathrm{~mm}$ and a diameter of $20 \mathrm{~mm}$. The $\mathrm{Pb}$ surfaces were carefully polished to provide a smooth, oxide-free surface. Rainwater $(\mathrm{pH}=8)$ was selected as the wetting agent. Rainwater was periodically (every 1 hour) dropped onto several fixed points at the $\mathrm{Pb}$ surface. Immediately before the SEM and FTIR analyses, an extra drop of rainwater was applied at the disc surface to observe the kinetics of any secondary $\mathrm{Pb}$ mineral formation.

\section{RESULTS AND DISCUSSIONS:}

Figure 1 shows the main $\mathrm{Pb}$ compounds identified in Range 5 samples based on the analysis of the recovered $\mathrm{Pb}$ bullet fragments by XRD. It can be seen that the predominant $\mathrm{Pb}$ species were metallic $\mathrm{Pb}$, cerussite, hydrocerussite, and litharge. Cerussite and hydrocerusssite are most likely to form at a $\mathrm{pH}$ of 8.4 (Dario, 1994; Hillier, 2001). Range 5 soil pH was approximately 8.2, which provided a nearly optimum $\mathrm{pH}$ condition for the growth of these secondary minerals. Optical, polarizing and Scanning Electron Microscopy were used to examine the surface of retrieved $\mathrm{Pb}$ bullet fragments from the Goldstone site. As it can be seen in the optical microscope photograph shown in Figure 2, Pb bullet fragments were covered by cerussite, a white powder. Further analyses by means of XRD (Figure 3) indicated that the predominant $\mathrm{Pb}$ species in Goldstone were hydrocerussite and metallic $\mathrm{Pb}$.

In addition, laurionite $(\mathrm{PbClOH})$ was also identified. Laurionite is an orthorhombicdipyramidal crystal. It is a famous mineral from the ancient deposits at Laurium, Greece, where it formed by the action of salty water on slags. It also occurs rarely in other oxidized zones over ore deposits. Further SEM investigation (Figure 4) confirmed the presence of laurionite in Goldstone samples. The high salt content of the evaporitic deposits (playa soil) provides with readily available chloride (Cl) anions leading to the formation of this kind of $\mathrm{Pb}$ compound. (Wu Chang-Yu and Pratim Biswas, 1996). The SEM analysis of a small $\mathrm{Pb}$ fragment recovered from Range 5 demonstrated the formation of cerussite on the surface of the metallic $\mathrm{Pb}$ pellet. 


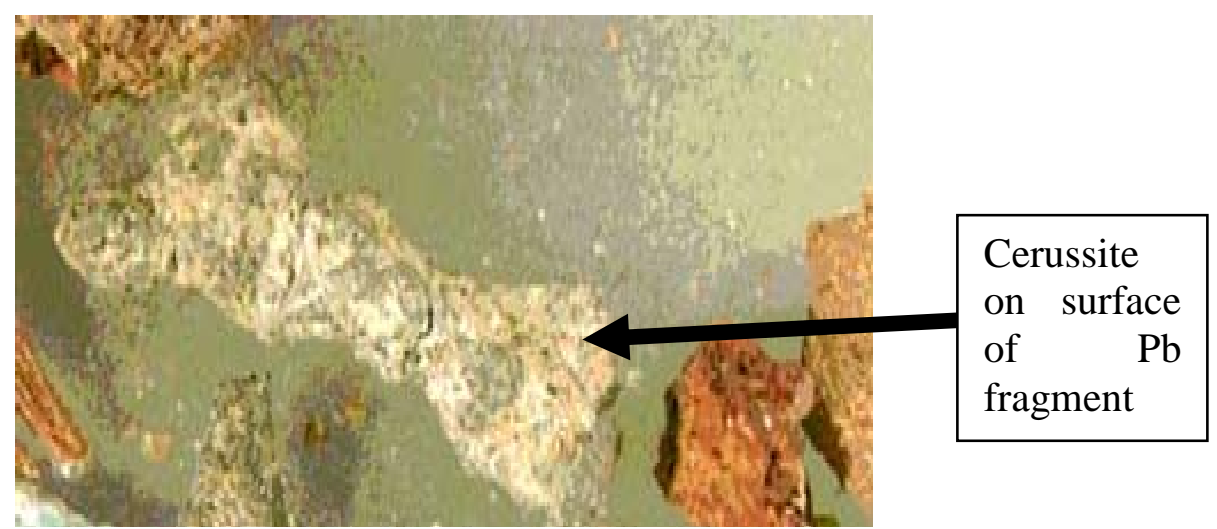

Figure 2. Optical microscope photograph depicting cerussite formation on the surface of a $\mathrm{Pb}$ bullet fragment (Goldstone firing range).

\section{Goldstone- Lead minerals}

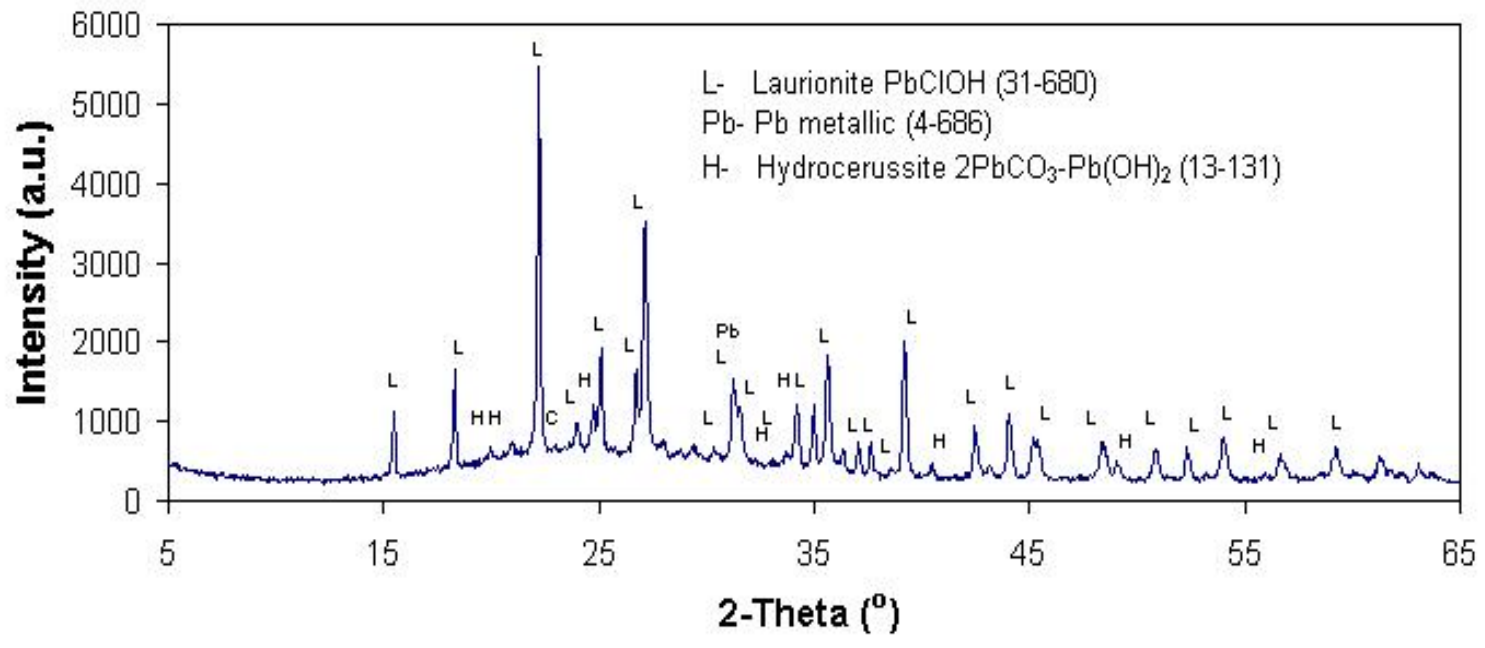

Figure 3. Diffraction pattern of crust minerals of metallic $\mathrm{Pb}$ particles recovered from the Goldstone site.

In Figure 5, the relatively smooth surface indicated the absence of any significant oxidation. Conversely, in Figure 6, upon increasing the SEM magnification by 100 times, a large number of cerussite crystals can be seen as $\mathrm{Pb}$ surface overgrowths. Cerussite can be readily identified by SEM owing to its orthorhombic-dipyramidal structure.Laboratory simulation studies of metallic surface reactions showed that during wetting and drying cycles, a white residue covers the metallic $\mathrm{Pb}$ surfaces. This periodic wetting and drying cycle test provided aggressive corrosive conditions for $\mathrm{Pb}$ as well as most other metals. Surface formations were analyzed by combination of SEM, XRD and $\mu$ FTIR.

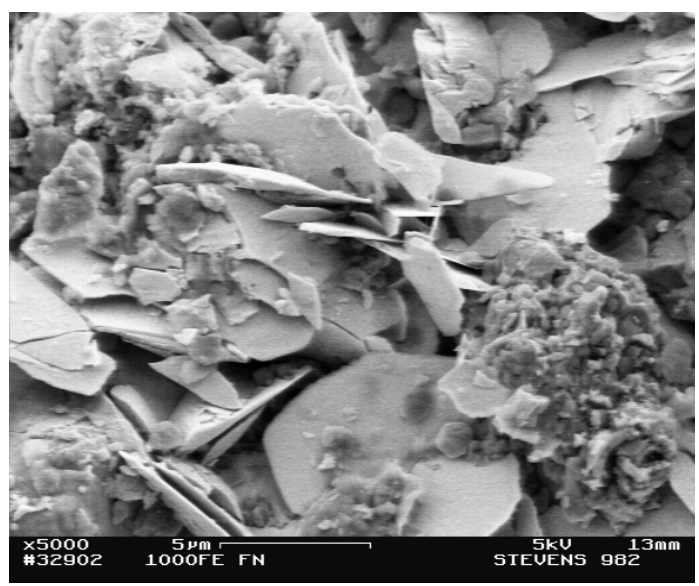

Figure 4. SEM picture of Laurionite $(\mathrm{PbClOH})$ crystals on $\mathrm{Pb}$ particles surface (Goldstone). 


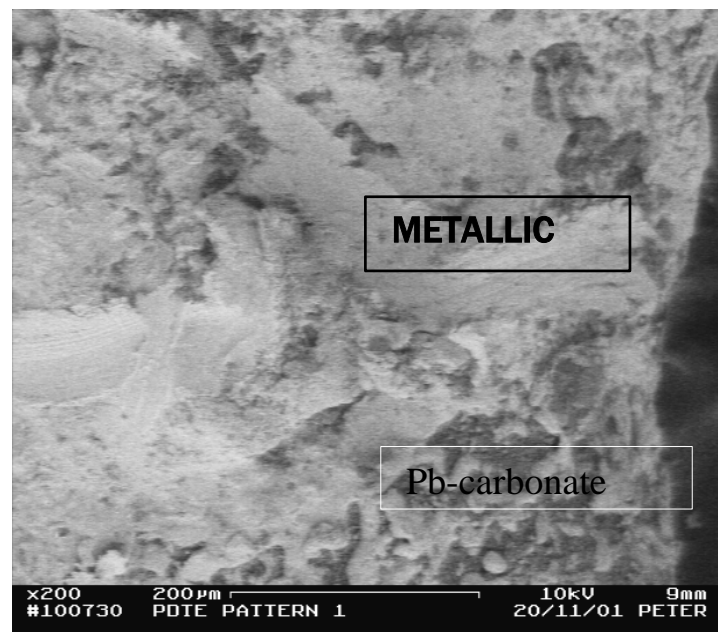

Figure 5. SEM pictures showing a relatively fresh $\mathrm{Pb}$ particle, where metallic $\mathrm{Pb}$ surfaces could be identified (Range5).

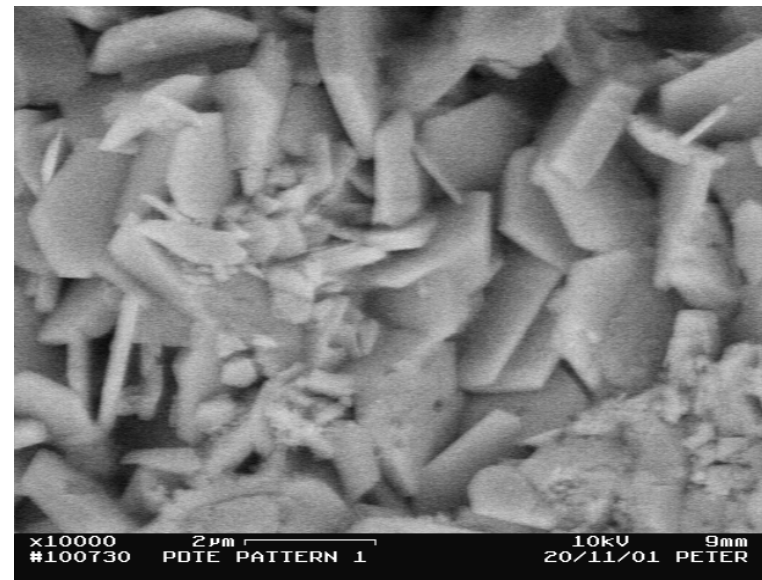

Figure 6. SEM picture showing cerrusite crystal overgrowth on metallic $\mathrm{Pb}$ surface (Range 5).

In Figure 7, some hydrocerussite crystals are shown in the left part of the Pb surface on which the rainwater had been dropped 2 minutes before the analysis, whereas the dry part still remained unoxidized. Figures 8 and 9 illustrate the formation of trigonal-ditrigonal pyramidal hydrocerussite crystals on the surface of metallic $\mathrm{Pb}$ immediately after one cycle of the wettingdrying process. As indicated in Figure 10, hexagonal plumbonacrite crystals were also formed after subsequent cycles of wetting and drying.

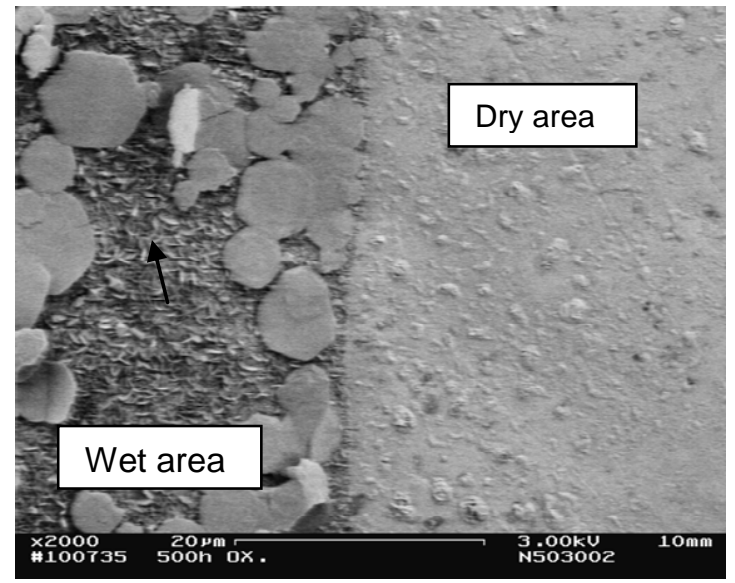

Figure 7. SEM picture showing hydrocerussite crystal development on a metallic $\mathrm{Pb}$ surface (laboratory weathering simulation).

Finally, cerussite eventually formed following repeated wetting-drying cycles due to the increased contact with available $\mathrm{CO}_{2}$ from the ambient environment, as depicted in Figure 11.

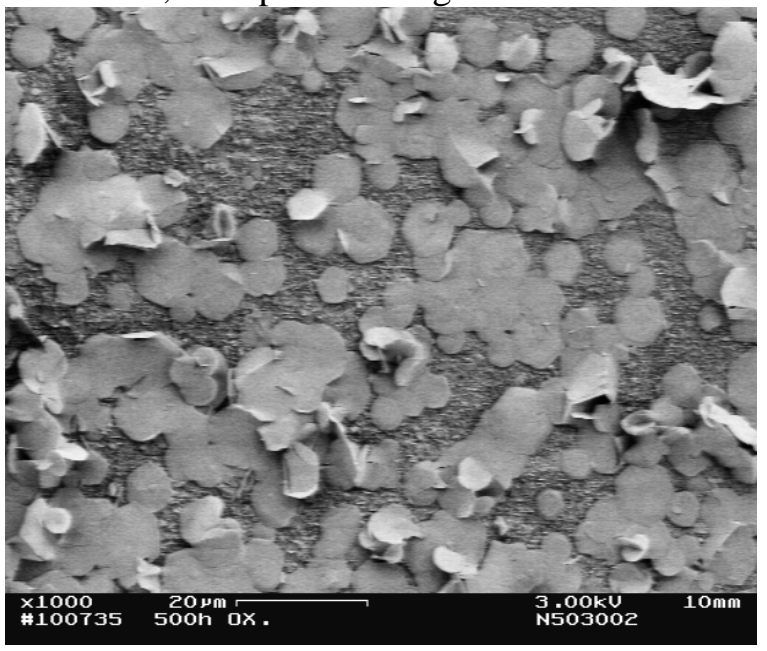

Figure 8. SEM picture showing hydrocerussite crystals on surface of metallic $\mathrm{Pb}$ formed after one cycle of wetting drying process (laboratory weathering simulation).

In order to focus on an area that provides optimal evidence of the weathering effect, the surface of the weathered $\mathrm{Pb}$ disk from laboratory simulation test was scanned using SEM prior to $\mu$-FTIR analysis. Figure 12 describes the scenario of hydrocerussite forming on the $\mathrm{Pb}$ disk approximately along the [001] direction using $\mu$-FTIR analysis. 


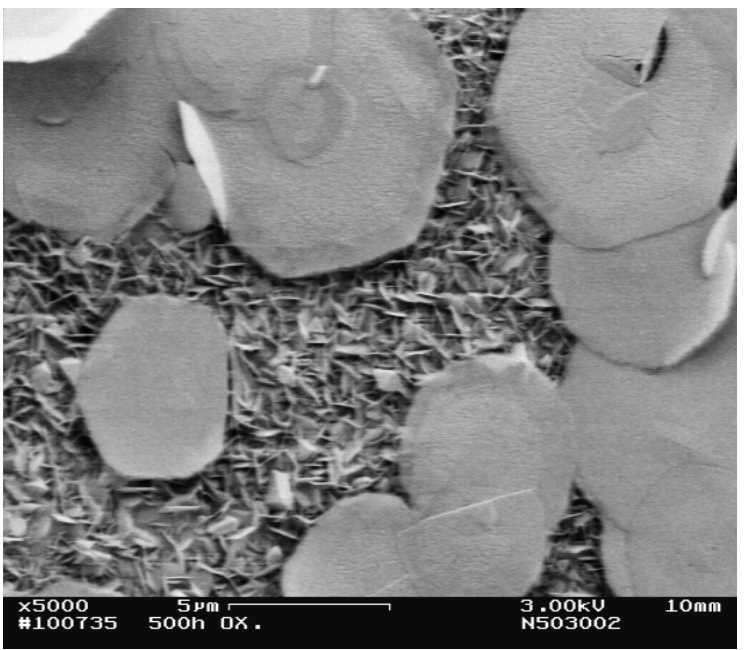

Figure 9. Close-up SEM pictures showing hydrocerussite crystals (laboratory weathering simulation).

The hydrocerussite formation was conclusively confirmed by its characteristic peaks derived from that designated area.

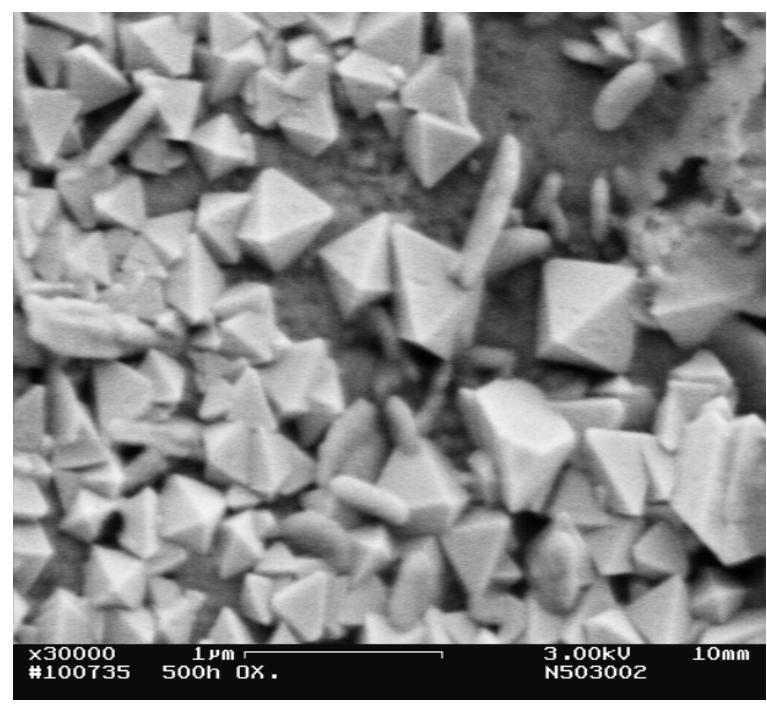

Figure 10. SEM picture showing plumbonacrite crystals formation during a subsequent wetting-drying cycle (laboratory weathering simulation).

Overall, the wetting and drying laboratory $\mathrm{Pb}$ weathering simulation test results along with the firing range field results suggested that the surface development of metallic $\mathrm{Pb}$ is a complex process affected by many factors (climate, $\mathrm{pH}$, soil type, etc.).

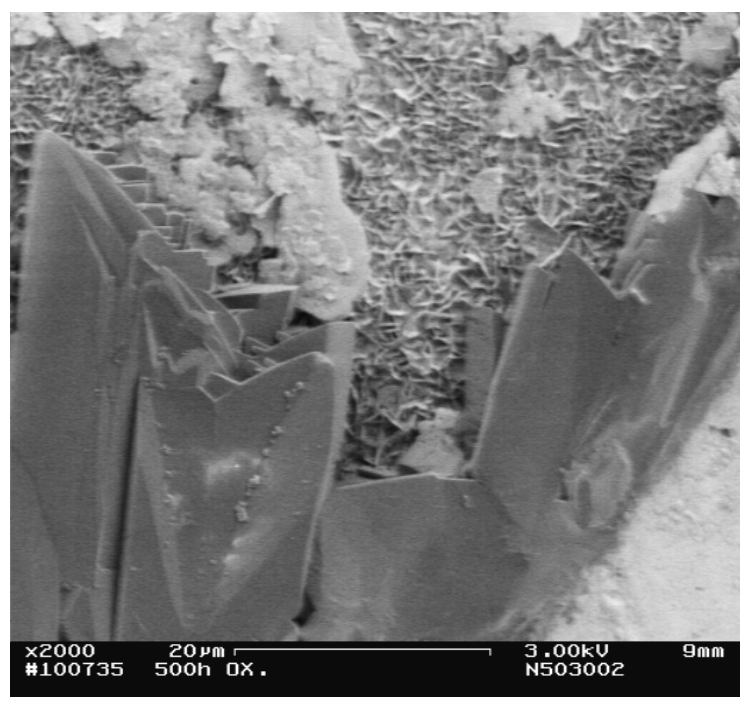

Figure 11 SEM picture showing cerussite crystals form during repeated wetting-drying cycles (laboratory weathering simulation).

The data suggest that several surface reactions occur sequentially. These could be summarized as follows:

$\mathrm{Pb}+\mathrm{H}_{2} \mathrm{O} \rightarrow \mathrm{Pb}(\mathrm{OH})$

$\mathrm{Pb}(\mathrm{OH})_{2}+\mathrm{CO}_{2} \rightarrow \mathrm{Pb}_{3}\left(\mathrm{CO}_{3}\right)_{2}(\mathrm{OH})_{2}$ Hydrocerussite

$\mathrm{Pb}_{3}\left(\mathrm{CO}_{3}\right)_{2}(\mathrm{OH})_{2}+\mathrm{H}_{2} \mathrm{O}+\mathrm{CO}_{2} \rightarrow \mathrm{Pb}_{10}\left(\mathrm{CO}_{3}\right)_{6}(\mathrm{OH})_{6} \mathrm{O}$

Plumbonacrite

$\mathrm{Pb}_{10}\left(\mathrm{CO}_{3}\right)_{6}(\mathrm{OH})_{6} \mathrm{O}+\mathrm{CO}_{2} \rightarrow \mathrm{PbCO}_{3}$ Cerussite $+\mathrm{H}_{2} \mathrm{O}$

Overall the above reactions will be assisted by the presence of atmospheric carbon dioxide. Moreover, in the presence of $\mathrm{Cl}$, laurionite will form.

\section{CONCLUSIONS}

Overall, the results indicate that in a high $\mathrm{pH}$ desert environment $\mathrm{Pb}$ would eventually form relatively 


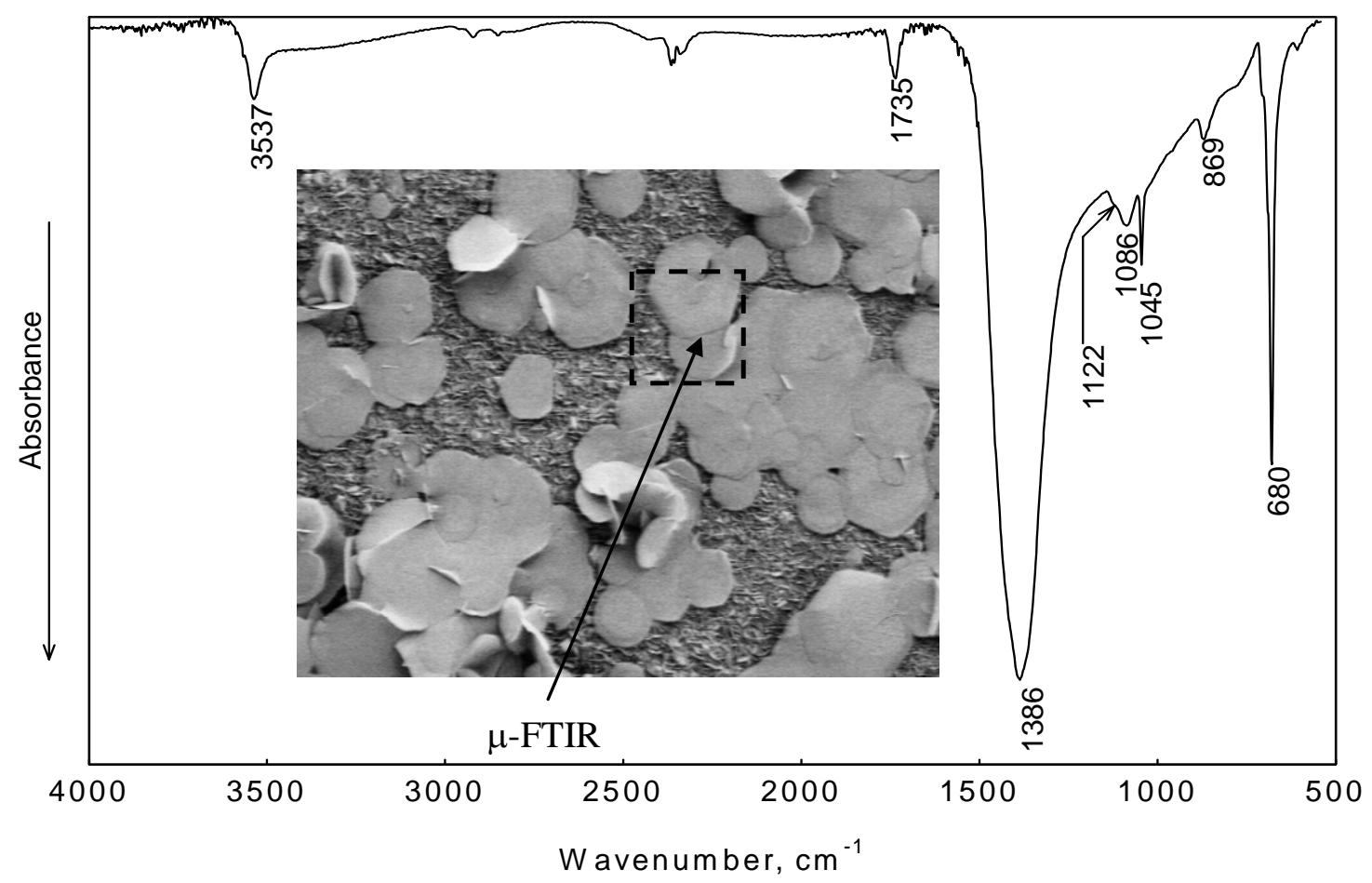

Figure 12. $\mu$-FTIR of hydrocerussite $\mathrm{Pb}_{3}\left(\mathrm{CO}_{3}\right)_{2}(\mathrm{OH})_{2}$ formed on the $\mathrm{Pb}$ disk approximately along [001] direction; a SEM picture was also embedded in the figure, specifying the designated area studied (laboratory simulation).

insoluble secondary minerals and therefore, its mobility is expected to be quite limited. The predominant $\mathrm{Pb}$ species identified by XRD in the active firing range (Range 5) soils included cerussite and hydrocerussite. Litharge $(\mathrm{PbO})$ and metallic $\mathrm{Pb}$ were also identified. In the abandoned firing range (Goldstone), hydrocerussite and metallic $\mathrm{Pb}$ were the major $\mathrm{Pb}$ species identified by XRD. Laurionite was also detected. These results were also confirmed by SEM analyses. A laboratory method to simulate metallic $\mathrm{Pb}$ weathering in soil environments was successfully established. The laboratory $\mathrm{Pb}$ weathering simulation results also confirmed the predominant presence of cerussite and hydrocerussite by both XRD and SEM. Plumbonacrite was also identified. Moreover, the first step in the $\mathrm{Pb}$ weathering sequence (formation of hydrocerussite) was also confirmed by means of FTIR spectroscopy. These $\mathrm{Pb}$ weathering sequence species tend to mostly form as surface overgrowths directly onto $\mathrm{Pb}$ bullet fragments. Based on these mineralogical and micromorphological observations a set of reaction series was hypothesized. These reactions describe the mechanisms of $\mathrm{Pb}$ weathering in desert environments and identify the associated physico-chemical transformations of metallic $\mathrm{Pb}$.

\section{REFERENCES}

Astrup T., Boddum J.K. and Christensen T.H. (1999), Lead distribution and mobility in a soil embarkment used as a bullet stop at a shooting range, Journal of soil contamination, 8, 653-665.

Bruell R., Nikolaidis N.P. and Long R.P. (1999), Evaluation of remedial alternatives of lead from shooting ranges soils, Environmental Engineering Science, 16, 403-414.

Craig, J.R (1999), Surface water transport of lead at a shooting range, Bull. Environ. Contam. Toxico., 63, 312-319.

Dario, M. (1994), Lead precipitation in the presence of sulphate and carbonate: testing of thermodynamic predictions, Water Research, 29, 74-87. 
Jorgensen, S.S. and Willems, M. (1987), The transformation of lead pellets in shooting range soils, Ambio., 16, $11-15$.

Lanndsberger S., Iskander F., Basunis S., Barnes D. and Kaminski M. (1999), Lead and copper contamination of soil from industrial activities and firing ranges, Biological Trace Element Research, 71, 387-396.

Lin Z., Comet B., Qvarfort U. and Herbert R. (1995), The chemical and mineralogical behavior of $\mathrm{Pb}$ in shooting range soils from Central Sweden, Environmental Pollution, 89, 303-309.

Murray K., Bazz I.A. and Sokol. H. (1997), Distribution and mobility of lead in soils at an outdoor shooting range, J. Soil Contam, 6, 79-93.

Nettleton W.D., Witty J.E., Nelson R.E. and Hawley J.W. (1975), Genesis of argillic horizons in soils of desert areas of the Southwestern United States, Soil Sciences of America Proceedings, 39, 919926.

Rooney C.P., McLaren R.G. and Cresswell R.J. (1999), Distribution and phytoavailahility of lead in a soil contaminated with lead shot, Water, Air, Soil Pollut., 116, 535-548.

Hillier, S. (2001), Quantitative determination of cerussite by X-ray powder diffraction and inferences for lead speciation and transport in stream sediments from a former lead mining area in Scotland, Applied Geochemistry, 6, 597-608.

USEPA (1996), Soil Screening Guidance: User's Guidance EPA 540/R-96/018, Office of Solid and Emergency Response, Washington DC.

USGS (2002), Lead in December 2001, Mineral industry survey, USGS (U.S. Geological Survey) Minerals Information Publications Services, 984 National Center, Reston, Viginia.

Wu Chang-Yu and Pratim Biswas (1996), Study of chlorine effects on the aerosol formation of lead species in multicomponent high-temperature environments, Journal of Aerosol Science, 4, 661.

Xintiuas, C. (1992), Impact of Lead-Contaminated Soil on Public Health, ATSDR/TP-92/12, (Agency for Toxic Substances and Disease Registry, USDHHS (US Department of Health and Human Services), Atlanta, GA. 